\title{
Sofrimento psíquico dos universitários de enfermagem no contexto da vida acadêmica
}

Psychic suffering of university nurses in the context of academic life

El sufrimiento psicológico de los estudiantes de enfermería en el contexto de la vida académica

\section{Deivson Wendell da Costa LimaI, Jaciara Sampaio Gonçalves ${ }^{\text {II }}$, Lívia Dayane Sousa Azevedo ${ }^{\text {III }}$ Alcivan Nunes Vieira ${ }^{\mathrm{IV}}$, Rosane Pilot Pessa ${ }^{\mathrm{v}}$, Margarita Antonia Villar Luis ${ }^{\mathrm{VI}}$}

\begin{abstract}
Resumo: Objetivo: analisar o sofrimento psíquico entre universitários de enfermagem no contexto da vida acadêmica. Método: pesquisa descritiva, de abordagem qualitativa, realizada com 20 universitários do último semestre de enfermagem, de uma universidade pública no Nordeste, Brasil. Os dados foram produzidos por perguntas abertas, entre março de 2016 a fevereiro de 2017, e avaliados pela análise de conteúdo. Resultados: os motivos de sofrimento psíquico foram as dificuldades de adaptação dos universitários no início do curso, conflitos durante a formação e expectativas quanto ao término da graduação. Diante disso, as consequências identificadas foram dificuldades alimentares, estresse e sintomas de depressão. Os modos de viver dos universitários são influenciados pelas vivências acadêmicas, inclusive os hábitos alimentares, excesso de trabalho e falta de lazer. Eles podem ser precursores de problemas graves de saúde, como ideação suicida. Conclusão: sugere-se ampliar estratégias de prevenção e manejo clínico na universidade articulado aos serviços de saúde mental.
\end{abstract}

Descritores: Enfermagem; Saúde mental; Sofrimento psíquico; Estudantes de enfermagem; Universidades

Abstract: Objective: to analyze the psychic suffering among nursing students in the context of academic life. Method: descriptive research, with a qualitative approach, carried out with 20 university students from the last semester of nursing, from a public university in the Northeast, Brazil. The data were produced by open-ended

\footnotetext{
I Enfermeiro, mestre, Universidade de São Paulo, Ribeirão Preto, São Paulo, Brasil. E-mail: deivsonwendell@gmail.com, Orcid: https://orcid.org/0000-0002-7020-2172

II Enfermeira, especialista, Universidade do Estado do Rio Grande do Norte, Mossoró, Rio Grande do Norte, Brasil. E-mail: jaciara_sampaio22@hotmail.com, Orcid: https://orcid.org/0000-0002-0708-9349

III Nutricionista, graduada, Universidade de São Paulo, Ribeirão Preto, São Paulo, Brasil. E-mail: liviaazevedo.nutri@gmail.com, Orcid: https://orcid.org/0000-0002-0019-9342

IV Enfermeiro, doutor, Universidade do Estado do Rio Grande do Norte, Mossoró, Rio Grande do Norte, Brasil. E-mail: alcivan_nunes@yahoo.com.br, Orcid: https://orcid.org/0000-0003-4222-6262

V Nutricionista, doutora, Universidade de São Paulo, Ribeirão Preto, São Paulo, Brasil. E-mail: rosane@eerp.usp.br, Orcid: https://orcid.org/0000-0002-6301-6830

VI Enfermeira, doutora, Universidade de São Paulo, Ribeirão Preto, São Paulo, Brasil. E-mail: margarit@eerp.usp.br, Orcid: https://orcid.org/0000-0002-9907-5146
} 
questions, between March 2016 and February 2017, and evaluated by content analysis. Results: the reasons for psychological suffering were the difficulties of adapting the university students at the beginning of the course, conflicts during training and expectations regarding the end of graduation. Given this, the consequences identified were dietary difficulties, stress and symptoms of depression. The way of life of university students is influenced by academic experiences, including eating habits, overwork and lack of leisure. They can be precursors of serious health problems, such as suicidal ideation. Conclusion: it is suggested to expand prevention and clinical management strategies at the university linked to mental health services.

Descriptors: Nursing; Mental health; Psychological suffering; Students, nursing; Universities

Resumen: Objetivo: analizar el sufrimiento psicológico en estudiantes de enfermería en el contexto de la vida académica. Método: investigación descriptiva, con enfoque cualitativo, realizada con 20 estudiantes universitarios del último semestre de enfermería, de una universidad pública del Noreste, Brasil. Los datos se elaboraron mediante preguntas abiertas, entre marzo de 2016 y febrero de 2017, y se evaluaron mediante análisis de contenido. Resultados: los motivos del sufrimiento psicológico fueron las dificultades de adaptación de los universitarios al inicio del curso, los conflictos durante la formación y las expectativas sobre el final de la graduación. Ante esto, las consecuencias identificadas fueron dificultades dietéticas, estrés y síntomas de depresión. La forma de vida de los estudiantes universitarios está influenciada por las experiencias académicas, incluidos los hábitos alimentarios, el exceso de trabajo y la falta de ocio. Pueden ser precursores de problemas de salud graves, como la ideación suicida. Conclusión: se sugiere ampliar las estrategias de prevención y manejo clínico en la universidad vinculadas a los servicios de salud mental.

Descriptores: Enfermería; Salud mental; Sufrimiento psíquico; Estudiantes de enfermería; Universidades

\section{Introdução}

O contexto acadêmico traz, para o universitário, uma vivência diferenciada e mais complexa do ensino médio. Exige a realização de pesquisas, a socialização com novos colegas e professores, o cumprimento das regras institucionais e aos conteúdos de aprendizagem, que podem contribuir para situações de sofrimento psíquico. ${ }^{1}$

Neste estudo, foi utilizado o conceito de sofrimento psíquico, caracterizado como uma manifestação de questões subjetivas que ocasionam desconforto emocional e relacional, malestares psíquicos e dificuldades em lidar com a vida pessoal, familiar ou social. ${ }^{2}$ Fundamentouse na referência ao modelo de atenção psicossocial que embasa a Reforma Psiquiátrica do Brasil; parte de uma apreensão da trama da existência dos universitários na sua situação de vida, que se 
dá nas relações cotidianas e em um espaço de tempo, em que estão presentes determinantes biológicos, econômicos, culturais e sociais. ${ }^{3}$

Na universidade, o jovem depara-se com mudanças pessoais, familiares e sociais que têm repercussão direta em suas vidas. Ele é exposto às variadas situações que mobilizam seu sofrimento psíquico, tais como: afastamento do âmbito familiar, conflitos amorosos, adaptações às exigências impostas pelo meio acadêmico e expectativas diversas em relação ao futuro profissional. Todas essas mudanças poderão levar o jovem ao sofrimento psíquico e vir a comprometer seu processo de aprendizagem no início, meio ou fim do curso de graduação. Cada uma dessas fases é marcada por diferentes demandas que podem ajudar na compreensão da saúde mental desse grupo populacional., ${ }^{1,4-5}$

Pesquisa nacional, realizada com graduandos de Instituições Federais de Ensino Superior, identificou dificuldades que mais afetam o desempenho acadêmico. Em destaque, a falta de disciplina de estudo (28,4\%), as dificuldades financeiras $(24,7 \%)$, a carga excessiva de trabalhos estudantis $(23,7 \%)$, os problemas emocionais $(23,7 \%)$ e o tempo de deslocamento para a universidade (18,9\%). ${ }^{6}$ Tais aspectos do contexto acadêmico têm contribuído para o aumento do número de estudantes em sofrimento psíquico, pois exigem mudanças comportamentais para se adaptarem e se organizarem para as demandas acadêmicas..$^{1,5}$

Estima-se que os universitários sejam mais vulneráveis ao desenvolvimento de sofrimento psíquico quando comparados com adultos jovens que não vivenciam esta realidade. ${ }^{5}$ Estudos apontam que cerca de 41 a 43,5\% dos graduandos em enfermagem poderão apresentar algum sofrimento psíquico durante sua formação. ${ }^{7-8}$ Além disso, foi evidenciado que quanto pior a adaptação à universidade, maior é a probabilidade de ocorrência de sofrimento psíquico. ${ }^{8}$ Diante dessa problemática, tem-se como questão de pesquisa: como o sofrimento psíquico dos graduandos de enfermagem pode estar relacionado à sua vida acadêmica? 
Sofrimento psíquico dos universitários de enfermagem no contexto da vida acadêmica 4

Esta pesquisa traz uma discussão importante para o universo acadêmico, uma vez que a universidade é compreendida como uma instituição de formação de sujeitos, articuladora e promotora do saber, um ambiente que contribui para a estabilidade, controle e ordenamento, ao invés de potencializar situações de sofrimento psíquico para seus estudantes.-5,8 Dessa forma, buscou-se analisar o sofrimento psíquico entre universitários de enfermagem no contexto da vida acadêmica.

\section{Método}

Pesquisa descritiva, de abordagem qualitativa, realizada em uma universidade pública do interior do Nordeste, Brasil. A população foi selecionada por meio de amostragem proposital, em que foram considerados os universitários matriculados no último semestre do curso de graduação em enfermagem da referida instituição.

Conforme acordado previamente com a direção do curso de graduação de enfermagem, a abordagem aconteceu por meio de um encontro para entrega de uma carta convite aos universitários em uma sala de aula da instituição de ensino. Nesta ocasião, todos os possíveis participantes estavam presentes, universo total de 22 em 2016 e 20 em 2017. Eles foram informados sobre o objetivo, a justificativa e a metodologia da pesquisa, além da garantia de anonimato e da liberdade de escolha em participar ou não da pesquisa. Aqueles que aceitaram participar foram agendados para realização da entrevista com definição de data, hora e local para coleta dos dados. Este agendamento teve o objetivo de não interferir na dinâmica de sua vida acadêmica. As entrevistas foram realizadas em uma sala da universidade, em local calmo e sem interrupções, mantendo a privacidade dos participantes do estudo.

Quanto aos critérios de inclusão, foi definido ser graduando em enfermagem, estar matriculado no último semestre e afirmar que teve sofrimento psíquico em algum momento de 
sua vida acadêmica. Os critérios de exclusão foram: estar em licença maternidade; em período de férias; ou com atestado por motivo de doença no período de coleta de dados.

A população da pesquisa foi composta por 42 universitários que estavam matriculados no último semestre do curso de graduação em enfermagem. Destes, oito não aceitaram participar do estudo e 14 não tiveram nenhum sofrimento psíquico relacionado ao contexto da universidade; já 20 deles relataram algum sofrimento psíquico vivenciado ao longo da sua formação acadêmica e foram incluídos como participantes na pesquisa.

Para a coleta de dados, apenas uma pesquisadora deste estudo foi responsável pela condução da entrevista semiestruturada, que tinha as seguintes questões orientadoras: Durante a sua permanência na universidade, até o presente momento, você vivenciou ou vivencia algum sofrimento psíquico? Quais foram os motivos que te levaram a esse sofrimento? Como as consequências desse sofrimento têm repercutido na sua vida?

As respostas foram gravadas com duração média de 45 minutos e, posteriormente, transcritas na íntegra, e não houve anotações durante ou após as entrevistas. Os dados foram coletados no período de março de 2016 a fevereiro de 2017, de acordo com a disponibilidade e concessão dos universitários por meio do Termo de Consentimento Livre e Esclarecido.

Com o intuito de manter o anonimato dos entrevistados e organização dos depoimentos, foi utilizada a letra “U” de universitário, seguida de algarismo arábico para identificá-los. A numeração aplicada não teve nenhuma relação com a ordem dos investigados. O material empírico foi processado por meio de análise de conteúdo, que se iniciou com a pré-análise, passando pela fase de exploração do material e finalizando com tratamento/interpretação dos resultados obtidos. Na primeira fase, foi realizada uma leitura flutuante das falas dos entrevistados, a fim de promover uma apropriação do conteúdo. Já a segunda, consistiu em uma leitura mais aprofundada do material a ser analisado, que possibilitou a definição das categorias emergentes, em torno das quais as falas foram organizadas. Na terceira e última, foram 
Sofrimento psíquico dos universitários de enfermagem no contexto da vida acadêmica | 6

construídas as categorias significativas por meio da interpretação do material analisado e estabelecidas às inferências, relacionando-as com os autores que auxiliam na discussão do estudo. ${ }^{9}$

A pesquisa foi aprovada pelo Comitê de Ética e Pesquisa em 26 de fevereiro de 2015, por meio do Parecer Consubstanciado número 970.857, segundo protocolo CEP/CAAE 41357215.3.0000.5294. Foram respeitadas as recomendações da Resolução 466/2012 que regem a pesquisa científica com seres humanos do Conselho Nacional de Saúde.

\section{Resultados}

Dos 20 entrevistados, 18 eram do sexo feminino, 16 solteiros e sem filhos, com idade variando entre 21 a 28 anos, 16 não trabalhavam, e 10 residiam em outras cidades. Quanto às características acadêmicas, 14 possuíam bolsa de estudo e 12 eram ingressantes na instituição por meio da política de cotas.

Os depoimentos dos universitários de enfermagem foram evidenciados e organizados em unidades de registro, de acordo com suas semelhanças e pertinência, que emergiu um quantitativo de 79 unidades de análise de conteúdo agrupadas em dez temas, que serão apresentadas em duas categorias: motivos do sofrimento psíquico dos universitários de enfermagem; consequências do sofrimento psíquico dos universitários de enfermagem.

$\mathrm{Na}$ primeira categoria, as dificuldades de adaptação no início do curso, os conflitos pessoais, afetivos e familiares durante a formação e as expectativas quanto ao término da graduação foram considerados os principais motivos do sofrimento psíquico pelos estudantes de enfermagem. Já a segunda categoria traz as consequências do sofrimento psíquico, manifestadas por meio das dificuldades alimentares, estresse e sintomas de depressão. 
Motivos do sofrimento psíquico dos universitários de enfermagem

No momento de ingresso na universidade, os alunos geram expectativas acerca de suas vivências no curso. A falta de conexão entre as expectativas e a realidade acadêmica podem fragilizar emocionalmente o graduando e dificultar sua adaptação inicial no curso, como é relatado no seguinte depoimento:

Quando eu entrei na universidade, estranhei muito e adoeci mentalmente. Eu vim de escola que não exigia muito do aluno. [...] Nos primeiros períodos do curso, pensei que enfermagem era uma coisa e foi bem diferente. Foi meu maior conflito, não queria continuar. Foi a fase que mais adoeci. (U19)

O novo ritmo de estudos no curso é mencionado como um dos motivos de sofrimento psíquico:

a gente tem muito conteúdo para estudar em pouco tempo, muita coisa para fazer [...] a rotina da faculdade é muito desgastante, de manhã e de tarde aula, à noite milhões de textos e de coisas para fazer. Então sofri muito por não conseguir conciliar tudo. (U7)

Outro motivo do sofrimento emergido pelos entrevistados é sobre o momento em que eles deixam as suas cidades de origem para morar em outro Estado ou município:

Tive que sair de casa para morar aqui. É difícil não ter mãe e pai para resolver as coisas. Você tem que se virar sozinho e isso é bem sofrido. (U5)

Um dos motivos que influencia no surgimento do sofrimento psíquico, durante o período acadêmico, está relacionado aos conflitos nas relações interpessoais, principalmente entre universitários e professores. Esta situação de sofrimento relatada aconteceu em sala de aula:

Teve um atrito com um dos professores de uma disciplina. Virou uma bola de neve porque os outros professores desta disciplina se envolveram [...] e isso me adoeceu, adoeceu muito a gente, quase toda turma adoeceu. (U13) 
Sofrimento psíquico dos universitários de enfermagem no contexto da vida acadêmica | 8

De acordo com os entrevistados, alguns docentes usavam do autoritarismo para se impor diante da turma e, com isso, os universitários se sentiam perseguidos, conforme é mostrado no depoimento a seguir:

Era a sensação de abuso de autoridade mesmo que alguns tinham com a turma toda [...] era perseguição com a gente, senti que era realmente perseguição contra a gente [...] tinham postura diferente do seu discurso, falavam muito em coletivo, mas não entendiam nossas dificuldades, não pararam para escutar nosso sofrimento. [...] A sobrecarga dessa disciplina e a forma que estes professores nos tratavam afetaram minha reprovação não nessa disciplina, mas em outra que era boa e não dei tanto valor. Esse problema aconteceu com vários da turma. (U9)

Os universitários relataram que os conflitos afetivos também foram motivos para o sofrimento psíquico durante a graduação:

Nunca consegui conciliar namoro e faculdade. Era trabalho em cima de trabalho, não tinha tempo para me dedicar a ninguém. (U19)

Eu tinha um relacionamento que não era muito saudável [...] tinha muitas coisas para fazer da faculdade, ele queria muito sair de casa para barzinho, shopping, praia. Eu era muito dependente e queria ir com ele. Eu não podia, sofria demais e ele não entendia. (U8)

Preocupações com os familiares motivaram o sofrimento psíquico e dificuldades de acompanhar as atividades exigidas pela vida acadêmica:

Vovó teve câncer quando eu estava no final do terceiro período da faculdade, ela foi diagnosticada com câncer de pulmão. Faltei muitos dias de aula para estar com ela. Sabia que iria me prejudicar no curso, mas queria estar com ela. (U20)

Eu fiquei bem abalada com o problema mental da minha mãe, não conseguia fazer mais nada direito. Ela é meu porto seguro. (U1)

O primeiro contato dos universitários com estágio supervisionado no hospital foi outro motivo contribuinte para o surgimento do sofrimento psíquico ao término do curso. Essas 
vivências proporcionaram o surgimento de sentimentos ambivalentes: por um lado estavam motivados para aprender o que é ser enfermeiro no hospital, mas por outro, preocupados em executar corretamente o que foi aprendido em sala de aula:

Queria muito chegar nos últimos períodos da faculdade, mas é preocupante quando você está ali no hospital com uma vida nas suas mãos, qualquer erro pode comprometer a vida ou a integridade da saúde daquela pessoa.(U6)

Outro motivo desencadeante do sofrimento psíquico mencionado pelos entrevistados refere-se à extensa carga horária do curso de enfermagem, a qual proporciona ao universitário uma sobrecarga de estudos. Alguns componentes curriculares dos períodos finais do curso são prejudicados pela condensação de muitos conteúdos em um único componente, resultando na elevada carga horária a ser cumprida em um curto espaço de tempo.

Eu teria tido bem menos problemas se eu não tivesse tanta sobrecarga aqui de trabalho. Esse período tem uma disciplina que concentra seis conteúdos que poderiam ser cada conteúdo uma disciplina. Foi muito sufocante e muito aperreio para gente, foi extremamente difícil. (U4)

Além da extensa carga horária de ensino do curso, foi possível identificar que os universitários se encontravam em sofrimento psíquico pela necessidade de participar de atividades de pesquisa e extensão:

Para melhorar seu currículo, para tentar crescer profissionalmente, a gente precisa se submeter a projetos de extensão, fazer pesquisa, isso tudo fora a carga horária das disciplinas. Aula de manhã e tarde e à noite para outras atividades. É um fardo, é muito sofrimento, tem horas que dar vontade de desistir. (U18)

O Trabalho de Conclusão de Curso (TCC) também foi mencionado pelos universitários como um dos motivos de sofrimento psíquico no término da graduação. A coincidência entre a elaboração do TCC, os estágios supervisionados e outras atividades acadêmicas implica em desgaste físico e sofrimento psíquico. 
Sofrimento psíquico dos universitários de enfermagem no contexto da vida acadêmica $\mid 10$

A gente vai de manhã e tarde todo dia para o estágio final do curso, quando chega em casa à noite estou extremamente cansada, não tenho mais energia para nada. Eu estou com dificuldade no TCC, de desenvolver, e é porque eu já estou a dois meses de entregar [...] não tem como você se dedicar que preste ao TCC porque a sobrecarga é muito grande. (U11)

E, por fim, outro motivo de sofrimento emergido nos períodos finais da vida acadêmica é a angústia relacionada ao futuro profissional:

Agora no final do curso fico pensando como será depois. Vou terminar e fazer o que? Deixarei de ser aluno para ser desempregado? Passarei logo em algum concurso? É muito angustiante tudo isso. (U15)

Todos acreditam que tudo vai melhorar depois que eu terminar a faculdade. O que esperam de mim? Me sinto pressionada pela sociedade de ser um bom profissional e pela familia em dar um retorno de tudo que investiram na minha formação. (U17)

Os depoimentos dos entrevistados ratificam que o transcurso da graduação configura como momentos de grandes dificuldades adaptativas, face às mudanças de hábitos, incertezas e desafios encontrados. Desta forma, os motivos do sofrimento psíquico não se limitaram a apenas realizar as atividades acadêmicas, mas àqueles que também envolviam as subjetividades desses estudantes, decorrentes do seu contexto de vida.

\section{Consequências do sofrimento vivenciado na vida dos universitários de enfermagem}

Os universitários relataram que a rotina na graduação em enfermagem é exaustiva e nessas condições não conseguem manter uma alimentação saudável. Ficam dependentes de alimentos de preparo rápido ou prontos com baixa qualidade nutritiva, e às vezes falham em realizar algumas refeições como justificativa pela falta de tempo:

com tanta coisa para fazer, eu penso: como vou preparar a comida? Algo que seja mais rápido e fácil. Vou lá na lanchonete e como um salgadinho com refrigerante bem rápido para voltar logo a faculdade. (U5) 
era tanta correria aqui na faculdade que eu só comia besteiras. As vezes esquecia de comer de dia e só a noite comia, aí comia muito. Era uma angústia que me fazia comer demais e dormir de menos (U14)

Passei dias sem comer, tinha dia que eu vinha para aula sem comer porque não tinha tempo de fazer a comida. Passava o dia todinho na faculdade sem comer nada, não tinha vontade de comer. Se não desse fome e se a barriga não doía, eu não comia. (U10)

A ocorrência do aumento ou perda de peso tem relação com as escolhas alimentares e pode influenciar a concentração, atenção, motivação e satisfação no contexto universitário.

Eu mal comia, eu só tinha tempo de fazer duas refeições no dia. Eu fiquei muito magra, mais do que já sou. Não conseguia me concentrar nas aulas de tão fraca. (U12)

Aumentei 13 quilos na faculdade em pouco tempo, cheguei com 58 quilos, hoje eu estou com 71 quilos, afetou minha autoestima. Quando estou ansiosa como demais. Não tenho vontade de ir para faculdade, me sinto feia e gorda. A gente sofre muito nesse processo de emagrece e engorda. Emagrecia devido a correria da faculdade, depois ficava ansiosa, comia mais e engordava (U9)

Outra consequência é o estresse vivenciado pelos universitários no ambiente acadêmico em busca de se adaptar as demandas relacionadas ao curso e à instituição.

Nosso curso é integral, uma sobrecarga imensa, tanta cobrança que me deixava facilmente estressada, chorava sempre. (U1)

Às vezes eu ficava estressada com a faculdade e até com raiva. Outras pessoas de outros cursos conseguem ter uma vida normal, ter lazer, passear, sair de casa, mas eu não consigo. A gente perde de fazer coisas que gosta, eu deixo de ficar com minha família, com meus amigos para dá conta das tarefas da faculdade. (U7)

Os universitários apresentaram sintomas físicos e psicológicos relacionados ao estresse, que prejudicavam seu desempenho acadêmico: 
Sofrimento psíquico dos universitários de enfermagem no contexto da vida acadêmica | 12

Meu estresse foi tão forte que tinha muitas dores de cabeça, pressão alta, falta de atenção, ciclo menstrual irregular, ficava fácil irritada e até agressiva. Não consegui ler os textos, não me concentrava. (U4)

Os sintomas de depressão surgem também como consequência da rotina diária dos universitários de enfermagem, que influencia suas relações familiares, afetivas, acadêmicas e sociais.

Todo dia eu chorava [...] fiquei mais triste, depressiva, fiquei mais calada em casa e mais sozinha. Eu sempre fui muito sensível, então eu chorava muito, chorava muito mesmo. Acho que tive depressão. Quando chegava em casa depois da faculdade chorava mais ainda. Sei que precisava de ajuda profissional, precisava de antidepressivos, mas não fui atrás. (U2)

Não tinha vontade de fazer nada. Não queria sair de casa, fiquei de cama por vários dias. Não tinha energia para preparar minha comida, não conseguia estudar. Durante a noite, ficava mais triste, chorava [...] tinha medo de dormir, medo de ter sonhos ruins. Tive todos os sintomas de depressão. (U16)

O entrevistado U3 descreve a depressão como uma reação às circunstâncias conflitantes e/ou como resposta às frustrações ou perdas vivenciadas:

eu tinha problemas de doença em casa e com a sobrecarga de estudos em disciplinas no final da faculdade fiquei mais depressiva. Estava tão depressiva que não queria sair de casa e vê ninguém, até meus pais. Quando chegaram os estágios, não sentia vontade de ir, não sentia preparada, acho que lembrava da doença da minha avó. É verdade ainda não sei lidar com perdas, com mortes. Quando a gente cai é porque já está com tanto peso nas costas que o que vier, seja pesado ou leve, é o suficiente para te derrubar. E comigo foi assim, eu acabei caindo em depressão, tomei psicotrópicos, fui diagnosticada com depressão por um psiquiatra. (U3)

Dentre os universitários que se referiram à depressão, houve o relato de alguma ideação suicida ou apresentaram histórico de tentativa de suicídio: 
Tinha várias coisas para fazer da faculdade, mas não conseguia. Minhas notas ficavam cada vez mais baixas, não tinha vontade de fazer nada. [...] Primeiro eu me entreguei a depressão, depois eu quase me matei, cheguei a pegar uma faca e ficar apertando-a na mão. Fiquei de três da manhã até sete da manhã sentado de frente do computador com o monitor desligado sem fazer nada porque eu estava com vontade de morrer, assim uma vontade que eu nunca senti na minha vida. [...] Nada na minha vida fazia mais sentido. (U10)

Identificou-se que os modos de viver e as condições de saúde destes estudantes são influenciados pelas vivências no contexto acadêmico, inclusive os hábitos alimentares, o excesso de atividades acadêmicas e a falta de lazer. Estas condições podem ser precursoras para o desenvolvimento de problemas mais graves de saúde, como exemplo a ideação suicida.

Desta forma, verificou-se que o contexto universitário contribuiu para que os estudantes desenvolvessem algum tipo de sofrimento psíquico e, como consequência deste sofrimento, foram gerados prejuízos aos demais aspectos de suas vidas.

\section{Discussão}

Os universitários pesquisados eram predominantemente do sexo feminino, jovens adultos, solteiros, sem filhos, não exerciam nenhuma atividade remunerada e residiam em outras cidades. Esta realidade apresenta características sociodemográficas semelhantes com estudo brasileiro realizado em uma cidade do Estado de São Paulo, Brasil. Universitários jovens e sem emprego são condições predisponentes para o sofrimento psíquico, que merecem atenção dos docentes e gestores das instituições de ensino. ${ }^{10}$

A entrada na universidade foi vista pelos entrevistados como um período de adaptações e fragilidade emocional. O sofrimento psíquico está diretamente relacionado com as exigências institucionais, ao ritmo de estudo e à distância da família. 
Sofrimento psíquico dos universitários de enfermagem no contexto da vida acadêmica | 14

Geralmente, a passagem do ensino médio para a universidade não é um processo fácil e simples. O contexto acadêmico exige a incorporação de novos padrões e costumes inerentes ao convívio social, constituindo-se como um espaço de adaptação às exigências do curso e às regras da instituição. ${ }^{11}$ Estas exigências influenciam o desenvolvimento de problemas emocionais, educacionais e relacionais dos discentes, e isto se agrava principalmente quando as expectativas deles não são atendidas logo ao entrar na universidade. ${ }^{2}$

A forma como as aulas são organizadas e divididas, o fracionamento do tempo em semestres, a densidade dos conteúdos e a quantidade de livros e textos para estudar fazem com que o universitário se veja diante de uma situação a qual necessita adaptar-se da melhor forma possível. Quando essa transição não ocorre, podem emergir, nesta fase, sentimento de frustração e de fracasso. ${ }^{11}$

O relatório do Fórum Nacional de Pró-reitores de Assuntos Comunitários e Estudantis (FONAPRACE) revelou que 16\% dos universitários queixam-se de situações vivenciadas na universidade. ${ }^{6}$ A família exerce importante papel na condução da vida do acadêmico e quando há o rompimento no convívio direto com seus familiares, esses universitários sentem-se receosos, inseguros e apresentam dificuldades em assumir novas responsabilidades relacionadas ao contexto de vida. ${ }^{8}$

Portanto, as dificuldades em assumir e conduzir essa realidade acadêmica podem emergir momentos de sofrimento psíquico e, consequentemente, até a desistência no início do curso de graduação. Para uma adaptação do universitário ao contexto acadêmico, considera-se então a necessidade de se desenvolverem ações institucionais para esses alunos neste processo de enfrentamento das mudanças. Outras questões importantes a serem abordadas são discussões sobre o que é uma universidade, projeto pedagógico do curso e o regimento da instituição de ensino superior. É preciso estabelecer espaços de discussão sobre as possíveis situações em que o universitário irá se deparar e como ele deverá agir diante dos problemas. 
15 | Lima DWC, Gonçalves JS, Azevedo LDS, Vieira AN, Pessa RP, Luis MAV

Os entrevistados mencionaram que os conflitos com professores, durante sua formação, foram um dos motivos para surgimento do sofrimento psíquico. O relacionamento entre professor-aluno pode favorecer ou não a saúde mental dos universitários. Eles buscam uma rede de apoio e um sentimento de pertencimento para lidar com as dificuldades a fim de se adaptarem com a realidade acadêmica. Entretanto, se existem impasses nas relações, isso pode gerar sofrimento. ${ }^{5}$

Esta relação professor-aluno é resultado de influências históricas da educação tradicional, que têm como característica a centralidade do processo formativo no professor que reproduz a imagem de um ser incontestável e inquestionável, como o único possuidor do saber. ${ }^{12}$ Para desconstrução deste modelo, é necessário promover atitudes menos rígidas e retrógradas no ambiente acadêmico, como espaços de escuta para maior aproximação entre os universitários e os professores. O uso de metodologias ativas de ensino, também, permite que os universitários assumam a autonomia de seu processo de construção de aprendizagem.

Foi constatado pelos universitários que os conflitos afetivos e familiares se constituíram como experiências de sofrimento psíquico durante a graduação. Muitas vezes, a rotina diária do graduando foi modificada pelo sentimento de insegurança em relação ao companheiro e pela preocupação com algum familiar doente. Estudo realizado com discentes do curso de enfermagem, em quatro instituições de ensino superior brasileiras, revelou que eles apresentaram dificuldade para gerenciar o tempo das atividades acadêmicas com as demandas pessoais, emocionais e sociais. ${ }^{13}$ Isto implica em poucos momentos de convívio familiar e social, que podem gerar a não adaptação do universitário, durante sua trajetória acadêmica, e aumento do risco à sua saúde mental. A construção de vínculos afetivos dentro e fora da universidade podem ser relevantes para o processo de ensino-aprendizagem, na permanência do universitário no curso e na melhoria da sua qualidade de vida. ${ }^{14}$ 
Sofrimento psíquico dos universitários de enfermagem no contexto da vida acadêmica | 16

A fase final da graduação foi considerada desafiadora pelos estudantes, ao exigir tomadas de decisões inerentes ao exercício profissional da enfermagem. A experiência do estágio permite que os alunos construam uma identidade na sua atuação e, consequentemente, a preocupação deles em demonstrar articulação do conhecimento teórico com situações reais, o que impulsiona a realizar o seu papel com qualidade, habilidade e segurança. ${ }^{15}$

A estrutura e organização do curso de enfermagem, o ritmo exacerbado de estudos e a rigidez dos horários contribuem para o esgotamento emocional dos universitários. Muitos não conseguem ter descanso e deixam de vivenciar momentos importantes, como uma atividade de lazer com seus familiares, amigos e companheiros. ${ }^{13-14}$

Ao chegar no final do curso, o TCC deveria estar em processo de finalização, pois sua construção é processual e se inicia desde o primeiro semestre. Entretanto, os entrevistados mencionaram que, por vezes, não conseguiam adequar e equilibrar os seus horários de estudos do TCC com as atividades dos estágios, em razão do cansaço e do tempo reduzido. Essas demandas acadêmicas obrigam mudanças comportamentais do estudante para enfrentar tais exigências, como novas rotinas de descanso, formas de organização do tempo e estratégias de estudo. $^{5}$

No final do curso de graduação em enfermagem, os estudantes disseram encarar momentos de medo, angústias e inseguranças diante das expectativas dos familiares e de um mercado de trabalho cada vez mais competitivo e seletivo. Diante desses sentimentos, surgem inquietações sobre as experiências vivenciadas na graduação, e se estas atenderão de forma suficiente às exigências para sua atuação profissional. ${ }^{16}$

Ressalta-se ainda que há limitações entre a oferta e a procura por trabalho pela enfermagem no Brasil. Isso contribui para aumento do número de enfermeiros que concluíram a graduação e, por falta de oportunidade, não se inserem no mercado de trabalho ou não exercem na área de formação ou atuam sem corresponder à sua realização profissional. ${ }^{17}$ 
Diante desses motivos de sofrimento psíquico vivenciados pelos universitários no início, durante e no final do curso, uma das consequências foram as dificuldades quanto à alimentação. Eles relataram que o consumo e o comportamento alimentar foram afetados pelo tempo, sentimentos, crenças, valores, habilidade culinária, recursos financeiros, variedade e acessibilidade aos alimentos. Estudo realizado com estudantes de graduação da área da saúde, de uma universidade pública brasileira, evidenciou que a ingestão alimentar habitual foi caracterizada pelo baixo consumo de grãos, vegetais e frutas e excesso de consumo de comidas rápidas, processadas e ultraprocessadas. ${ }^{18-19}$

Neste estudo, os estudantes relataram ter mais importância com o seu desempenho acadêmico do que com a qualidade de sua alimentação, o que pode gerar riscos à saúde. Outra pesquisa aponta uma maior prevalência de obesidade e sobrepeso do que de eutrofia e desnutrição entre universitários. Trata-se de uma realidade decorrente do baixo consumo de frutas e verduras, peixes e grãos integrais e pela redução na frequência de refeições e aumento no consumo de doces, bebidas açucaradas e alcoólicas. ${ }^{18-19}$ Estratégias para promover uma alimentação adequada e balanceada, com preferência aos alimentos in natura e minimamente processados, serão necessárias e valiosas para o desenvolvimento da promoção da saúde em instituições de ensino superior.

Outra consequência mencionada pelos universitários foi o estresse, que pode influenciar diretamente na saúde mental dos estudantes de enfermagem. Distância da família, novos relacionamentos interpessoais, enfrentamento do desconhecido, preocupação com o aprendizado e sobrecarga de atividades são situações estressantes de adaptação ao contexto acadêmico. Ao longo do curso, esses fatores estressores acentuam-se gradativamente, uma vez que cada fase requer dos estudantes o desenvolvimento de novos saberes e novas práticas. ${ }^{13-16}$

Os estudantes da área da saúde experenciam elevados níveis de estresse no processo de ensino-aprendizagem, sobretudo os alunos da graduação em enfermagem, pela necessidade de 
Sofrimento psíquico dos universitários de enfermagem no contexto da vida acadêmica | 18

promover um cuidado ético e humanizado. Estudo realizado com 190 graduandos de enfermagem de uma universidade pública brasileira, identificou uma prevalência de estresse em $79,5 \%$ deles. Os principais sintomas físicos identificados foram: o cansaço constante $(77,3 \%)$ e sensação de desgaste físico (76,8\%). Já os sintomas relacionados ao sofrimento psíquico foram: cansaço excessivo $(70,5 \%)$ e irritabilidade $(58,4 \%) .{ }^{20-21}$

Os sintomas de depressão também foram mencionados pelos universitários como consequência de suas vivências acadêmicas, que, por vezes, passam despercebidos ou são negligenciados. Eles relataram conviver com os sentimentos de frustação, angústia e tristeza, muitas vezes sem ajuda de um profissional, condição que pode se agravar no decorrer do curso. ${ }^{5}$

A pessoa acometida por depressão pode apresentar humor irritável, diminuição parcial ou total do humor e da capacidade de sentir prazer, diminuição da energia. Portanto, sente-se constantemente cansada e desanimada para realizar atividade do cotidiano, o que lhe causa malestar. Ela ainda pode se sentir indiferente, desinteressada e incapaz de projetar o futuro. ${ }^{22}$ Outro estudo identificou que graduandos de enfermagem pouco procuram acompanhamento de um serviço ou profissional de saúde mental; e dentre aqueles que fazem uso regular de psicotrópicos, $61 \%$ declararam uso de antidepressivos e $28 \%$ afirmaram usar benzodiazepínicos. ${ }^{7}$

Salienta-se que a depressão esteja mais presente nos períodos finais do curso pela preocupação com a qualidade do cuidado nos estágios ao lidar com situações de vida e morte, bem como pela decisão do futuro profissional, que envolvem autoconceito e identidade com a profissão. ${ }^{22}$ Pesquisa desenvolvida com 203 estudantes de enfermagem de uma universidade pública brasileira, revelou que dentre os participantes $19,2 \%$ apresentaram níveis moderados ou graves de depressão. ${ }^{23}$

Um dos entrevistados declarou ter ideação suicida atribuída às adversidades vivenciadas na universidade. Referiu tristeza profunda e desinteresse para atividades acadêmicas como consequências da falta de vontade de viver. A ideação suicida afeta cerca de 18,8\% dos 
universitários em todo mundo e tem forte associação com a presença de sintomas depressivos e baixo rendimento escolar..$^{24-26}$

As intervenções voltadas para a promoção da saúde mental nas universidades são incipientes, apesar do crescente número de estudantes em sofrimento psíquico ${ }^{7,8,24}$ sendo que neste estudo destacam-se os alunos do curso de graduação em enfermagem. Esta realidade reforça o importante papel dessas instituições na formulação de estratégias para minimizar as vulnerabilidades em saúde mental e promover qualidade de vida entre os universitários.

O estudo apresentou como limitação a realização somente de uma entrevista com os estudantes do último semestre do curso de uma única universidade. Sugere-se a organização de um núcleo de atenção em saúde mental no âmbito acadêmico, constituído por uma equipe multiprofissional, para realizarem estratégias de prevenção e manejo clínico, articulado com os profissionais dos serviços de saúde mental.

\section{Conclusão}

O sofrimento psíquico dos universitários está relacionado à sua trajetória acadêmica e diretamente implicado com o modus operandi da sua formação. Os motivos do sofrimento psíquico mencionados foram as dificuldades de adaptação no início do curso, conflitos pessoais, afetivos e familiares que emergiram durante sua vida acadêmica e expectativas quanto ao término da graduação. Identificou-se como consequências do sofrimento psíquico o surgimento de dificuldades alimentares, estresse e depressão.

Como propostas de intervenção nesta realidade, podem ser consideradas o Projeto Pedagógico do Curso e o processo formativo, que precisam levar em consideração a forma como os universitários lidam com o processo de formação e com a sua saúde mental. Sugere-se como mudanças curriculares, a reorganização da carga horária das disciplinas, aumento na extensão 
Sofrimento psíquico dos universitários de enfermagem no contexto da vida acadêmica $\mid 20$

do curso para dez períodos letivos, a avaliação de conteúdos e das metodologias de ensino, realização de atividades acadêmicas de forma ponderada com os objetivos de formação que considerem, também, as necessidades dos alunos em ter acesso ao lazer e de manter contato com a sua rede familiar e social.

\section{Referências}

1. Andrade AS, Tiraboschi GA, Antunes NA, Viana PVBA, Zanoto PA, Curilla RT. Vivências acadêmicas e sofrimento psíquico de estudantes de Psicologia. Psicol Ciênc Prof. 2016;36(4):831-46. doi: 10.1590/19823703004142015

2. Graner KM, Cerqueira ATAR. Integrative review: psychological distress among university students and correlated factors. Ciênc Saúde Colet. 2019;24(4):1327-46. doi: 10.1590/1413-81232018244.09692017

3. Braga CP. Perspective of deinstitutionalization: reading keys to understand a national mental health policy aligned with the psychiatric reform. Saúde Soc. 2019;28(4):198-213. doi: 10.1590/s010412902019190125

4. Brown JSL. Student mental health: some answers and more questions. J Ment Health. 2018;27(3):193-6. doi: 10.1080/09638237.2018.1470319

5. Ariño DO, Bardagi MP. Relação entre fatores acadêmicos e a saúde mental de estudantes universitários. Psicol Pesq. 2018;12(3):44-52. doi: 10.24879/2018001200300544

6. Fórum Nacional de Pró-Reitores de Assuntos Comunitários e Estudantis (FONAPRACE). V pesquisa nacional de perfil socioeconômico e cultural dos (as) graduandos (as) das IFES - 2018 [Internet]. Brasília (DF): FONAPRACE; 2019 [acesso em 2019 nov 23]. Disponível em: http://www.andifes.org.br/wpcontent/uploads/2019/05/V-Pesquisa-Nacional-de-Perfil-Socioecon\%C3\%B4mico-e-Cultural-dos-asGraduandos-as-das-IFES-2018.pdf

7. Silva PLBC, Silva BFF, Chagas KKACR, Tortola MBA, Caldeira RLR. Common mental disorders between nursing students and related factors. Rev Enferm Cent Oeste Min. 2019;9:e3191. doi: 10.19175/recom.v9i0.3191

8. Carleto CT, Moura RCD, Santos VS, Pedrosa LAK. Adaptation to university and common mental disorders in nursing undergraduate student. Rev Eletrônica Enferm. 2018;20:v20a01. doi: 10.5216/ree.v20.43888

9. Bardin L. Análise de conteúdo. São Paulo: Edições 70; 2011. 
10. Cachoeira DVAC, Santos SCC2, Meneganti APS, Negreiros NF, Cardoso L, Preto VA. Relação do perfil sociodemográfico com o risco de adoecimento por transtornos mentais comum em alunos do curso de enfermagem. Rev Enferm UFPE On Line [Internet]. 2016 [cited from 2019 Nov 23];10(12):4501-8. Available from: https://periodicos.ufpe.br/revistas/revistaenfermagem/article/view/11516

11. Sahão FT, Kienen N. Comportamentos adaptativos de estudantes universitários diante das dificuldades de ajustamento à universidade. Quad Psicol. 2020;22(1):e1612. doi: 10.5565/rev/qpsicologia.1612

12. Winters JRF, Prado ML, Waterkemper R, Kempfer SS. Dialogical and participative training in nursing education: contribution to the development of critical and reflective and creative thinking of students. REME Rev Min Enferm. 2017;21:e-1067. doi: 10.5935/1415-2762.20170077

13. Bublitz S, Guido LA, Lopes LFD, Freitas EO. Association between nursing students' academic and sociodemographic characteristics and stress. Texto Contexto Enferm. 2016;25(4):e2440015. doi: 10.1590/0104-07072016002440015

14. Carlesso JPP. The challenges of academic life and the psychic suffering of college students. Res Soc Dev. 2020;9(2):e82922092. doi: 10.33448/rsd-v9i2.2092

15. Rocha EN, Mantovani MF, Silva ATM, Hereibi MJ, Viante WJM, Kwiatkoski DR. Nursing students' perception of clinical competences. REME Rev Min Enferm. 2019;23:e-1179. doi: 10.5935/14152762.20190027

16. Almeida CAPL, Silva LQ, Rocha FCV, Batista MRFF, Sales MCV. Factors associated with the onset of stress in a sample of university nursing students. SMAD Rev Eletrônica Saúde Mental Alcool Drog. 2018;13(4):176-88. doi: 10.11606/issn.1806-6976.v13i4p176-188

17. Oliveira JSA, Pires DEP, Alvarez AM, Sena RR, Medeiros SM, Andrade SR. Trends in the job market of nurses in the view of managers. Rev Bras Enferm. 2018;71(1):160-7. doi: 10.1590/0034-7167-2016-0103

18. Loureiro MP. Nutritional status and dietary habits of college students. Rev Segur Aliment Nutr. 2016;23(2):955-72. doi: 10.20396/san.v23i2.8647612

19. Fernandes DPS, Conceição LL, Souza ECG, Ribeiro AQ, Duarte MSL. Food consumption in students of the health area of a Brazilian public university. Food Public Health. 2016;6(2):38-43. doi: 10.5923/j.fph.20160602.02

20. Cestari VRF, Barbosa IV, Florêncio RS, Pessoa VLMP, Moreira TMM. Stress in nursing students: study on sociodemographic and academic vulnerabilities. Acta Paul Enferm. 2017;30(2):190-6. doi: 10.1590/1982-0194201700029

21. Kestenberg CCF, Rosa BMS, Silva AV, Fabri JMG, Regazzi ICR. Stress in undergraduate nursing students. Rev Enferm UERJ. 2017;25:e26716. doi: 10.12957/reuerj.2017.26716 
Sofrimento psíquico dos universitários de enfermagem no contexto da vida acadêmica | 22

22. Gadassi R, Waser A, Gati I. Gender differences in the association of depression with career indecisiveness, career-decision status, and career-preference crystallization. J Couns Psychol. 2015;62(4):632-41. doi: 10.1037/cou0000113

23. Facioli AM, Barros AF, Melo MC, Ogliari ICM, Custódio RJM. Depression among nursing students and its association with academic life. Rev Bras Enferm. 2020;73(1):e20180173. doi: 10.1590/0034-71672018-0173

24. Paula W, Breguez GS, Machado EL, Meireles AL. Prevalence of anxiety, depression, and suicidal ideation symptoms among university students: a systematic review. Braz J Health Rev. 2020;3(4):8739-56. doi: 10.34119/bjhrv3n4-119

25. Santos HGB, Marcon SR, Espinosa MM, Baptista MN, Paulo PMC. Factors associated with suicidal ideation among university students. Rev Latinoam Enferm. 2017;25:e2878. doi: 10.1590/15188345.1592.2878

26. Veloso LUP, Lima CLS, Sales JCS, Monteiro CFS, Gonçalves AMS, Silva Júnior FJG. Suicidal ideation among health field undergraduates: prevalence and associated factors. Rev Gaúcha Enferm. 2019;40:e20180144. doi: 10.1590/1983-1447.2019.20180144

Editora Científica Chefe: Cristiane Cardoso de Paula

Editor associado: Daiana Foggiato de Siqueira

Fomento / Agradecimento: Não se aplica

\section{Autor correspondente}

Deivson Wendell da Costa Lima

E-mail: deivsonwendell@gmail.com

Endereço: Rua Prof. Hélio Lourenço, 3900, Monte Alegre, Ribeirão Preto-SP

CEP: $14040-902$

\section{Contribuições de Autoria}

\section{1 - Deivson Wendell da Costa Lima}

Planejamento e execução do estudo e redação do artigo.

\section{2 - Jaciara Sampaio Gonçalves}

Concepção do estudo, coleta e interpretação dos dados. 
23 | Lima DWC, Gonçalves JS, Azevedo LDS, Vieira AN, Pessa RP, Luis MAV

\section{3 - Lívia Dayane Sousa Azevedo}

Interpretação dos dados e redação do artigo.

\section{4 - Alcivan Nunes Vieira}

Interpretação dos dados e redação do artigo.

\section{5 - Rosane Pilot Pessa}

Revisão crítica do conteúdo do artigo e aprovação da versão final a ser publicada.

\section{6 - Margarita Antonia Villar Luis}

Revisão crítica do conteúdo do artigo e aprovação da versão final a ser publicada.

\section{Como citar este artigo}

Lima DWC, Gonçalves JS, Azevedo LDS, Vieira AN, Pessa RP, Luis MAV. Sofrimento psíquico dos universitários de enfermagem no contexto da vida acadêmica. Rev. Enferm. UFSM. 2021 [Acesso em: Anos Mês Dia]; vol.11 e23: 1-

23. DOI: https://doi.org/10.5902/2179769244220 